\title{
LOS INMIGRANTES MARROQUÍES EN ANDALUCÍA Y LAS POLÍTICAS DE COOPERACIÓN HISPANO-MARROQUÍES
}

\author{
Maria Carella ${ }^{1}$
}

\begin{abstract}
RESUMEN
El objetivo de esta investigación es analizar el flujo migratorio de marroquíes hacia el sur de España, a través de los residentes de esta nacionalidad en la Comunidad Autónoma de Andalucía. En la primera parte se analiza los orígenes y la evolución del flujo marroquí hacia España y la ubicación de los inmigrantes en los sectores laborales andaluces. La segunda parte se centra en el estudio de los acuerdos bilaterales, de los proyectos de cooperación y de las diferentes medidas adoptadas por España con la finalidad de limitar y reglamentar la movilidad marroquí. En el contexto de esta amplia problemática, otro objetivo es el de indagar sobre las respuestas de carácter político y demo-económico procedentes de la Junta de Andalucía, y sobre las tentativas de colaboración entre la misma y los países de la ribera sur del Mediterráneo.
\end{abstract}

Palabras claves: España, Andalucía, inmigración marroquí, política de cooperación hispano-marroquí.

\section{RIASSUNTO}

Lo scopo di questo lavoro é quello di analizzare il flusso migratorio dei marocchini verso il sud della Spagna, attraverso i residenti di questa nazionalitá nella Comunidad Autonma dell'Andalusia. Nella prima parte, si esaminano le origini e l'evoluzione del flusso marocchino e la collocazione degli immigrati sul mercato del lavoro andaluso. La seconda parte é focalizzata sullo studio degli accordi bilaterali, dei progetti di cooperazione e dei vari provvedimenti, adottati dalla Spagna al fine di limitare e regolamentare la mobilitá dei marocchini. Nel contesto di quest'ampia problematica, obiettivo sotteso della relazione è quello di indagare sulle «risposte» sia di carattere politico che demoeconomico giunte dalla Junta de Andalusia e sui tentativi di collaborazione tra la stessa ed i paesi della riva sud del Mediterraneo.

Parole chiave: Spagna, Andalusia, immigrazione marocchina, politica di cooperazione ispano-marocchina.

1 Becaria de la Universidad de Bari en el Departamento de Geografía Humana de la Universidad de Alicante (año académico 1997-1998). 


\section{Relaciones entre norte y sur en la cuenca del Mediterráneo}

Nunca como en los últimos años la cuenca del Mediterráneo ha representado una zona de conflictos sociales y de grandes contradicciones determinados esencialmente por el desequilibrio entre los países de las dos riberas. Las diferencias en el interior de esta área han producido un fuerte empuje migratorio desde el sur hacia el norte que ha transformado países tradicionalmente emisores de mano de obra en países de inmigración.

Desde finales de los años '70, Italia y España, en particular, se han convertido en el único lugar posible en Europa de los flujos de trabajadores procedentes desde la ribera sur del Mediterráneo por la proximidad geográfica y por el escaso control de las fronteras. Inicialmente considerados como «puertas de entrada» para poder acceder a los otros países europeos económicamente más fuertes, hoy estos dos países están considerados como metas de un fenómeno migratorio, la cual lógica no se basa en una estancia temporal, como en el pasado, sino al contrario, se inspira en una permanencia que en la mayoría de los casos es irreversible.

En lo que concierne particularmente a España, país de ingente emigración sobre todo transoceánica en los años '50 y ' 60 , ha vivido una inversión migratoria caracterizada por dos fases:

- en un primer momento, es decir, desde 1973, la crisis económica mundial ha generado principalmente corrientes migratorias de retorno de los emigrados españoles que antes de la segunda guerra mundial se habían dirigido a América Latina y luego hacia países de Europa Occidental;

- a partir de los años '80, el país ha experimentado una continua y consistente inmigración de extranjeros esencialmente originarios de las áreas menos desarrolladas, la cual se ha consolidado durante el decenio y ha modificado el rol del estado en lo que atañe a la dirección de los movimientos y los flujos migratorios internacionales.

Actualmente, se puede afirmar que España es un país de inmigración (el saldo migratorio de signo positivo confirma esta aseveración), aunque la presencia de individuos en condiciones irregulares o ilegales no permite contabilizar exactamente el volumen de los extranjeros presentes en el territorio.

\subsection{España meta de las migraciones del sur}

Según los datos oficiales, en 1996 se contabilizaron en España 538.984 extranjeros con permiso regular de residencia. Entre 1975 y 1996 su número ha aumentado, en cifras absolutas, del orden del $326 \%$ con una tasa de crecimiento anual del 5,8\%; en cambio, el flujo de entrada en la última década se ha duplicado pasando de 17.205 inmigrantes en 1984 a 35.104 en 1995, cifra que confirma la inversión migratoria comprobada en el país (cuadro 1).

De hecho, no se puede establecer con exactitud el contingente de los extranjeros que viven en el país, a causa del elevado número de clandestinos que llegan cada año, de cuya cifra no se han hecho estimaciones rigurosas.

Si nos atenemos al país de origen de los extranjeros, 274.081 llegan de Europa (equivalente al 50,8\% del contingente total que reside regularmente en España), que sigue siendo el continente que aporta un mayor número de extranjeros, de los cuales la mayoría proceden del Reino Unido (68.359), Alemania (45.898) y de Portugal (38.316). Entre los inmigrantes venidos de países no europeos, los latinoamericanos, asiáticos y africanos han aumentado a un ritmo muy elevado entre 1985 y 1991, aprovechando la relativa facilidad 


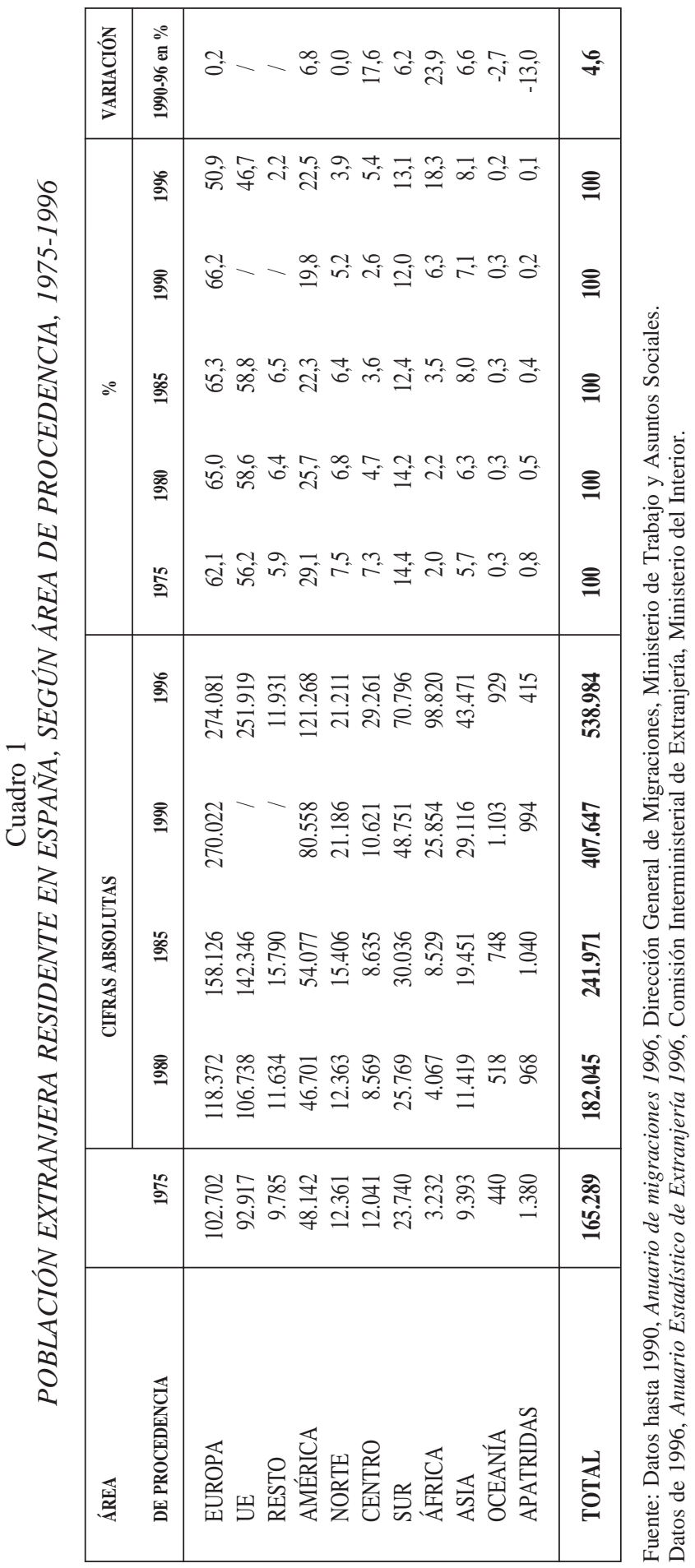


de entrada al país, en lo que sin duda influye su insuficiente preparación desde el punto de vista jurídico.

El cuadro descrito permite, grosso modo, una distinción entre dos grupos de inmigrantes: a) los de procedencia de los estados miembros de la Unión Europea que, como queda establecido en los artículos 8 y 8 a del Tratado CE, tienen derecho a circular libremente y residir en el interior del territorio de la U.E. debido a su condición de ciudadanos europeos. En lo que se refiere al Estado Español la permanencia de estos está reglamentada por R. D. 766/1992, modificado con posterioridad por el R. D. 737/1995. b) El resto, es decir, el grupo configurado por los pertenecientes a países no comunitarios, poseen un estado jurídico cuyo marco base o de referencia lo encontramos en la Ley Orgánica 7/85, o sea «Ley de Extranjería», la cual será tratada con posterioridad.

Las diferentes causas de la movilidad territorial permiten una nueva clasificación de los inmigrantes en España en «inactivos voluntarios y pensionistas», «profesionales cualificados», es decir, los procedentes del «mundo rico» (Europa Occidental y Estados Unidos), y «asilados políticos y refugiados» e «inmigrantes económicos» (Gozálvez Pérez 1995 a, Cordero del Castillo 1993). Los del primer grupo vienen a pasar los años de la «tercera edad» en las áreas turísticas del Mediterráneo, y los del segundo se emplean en puestos de responsabilidad de las grandes empresas. Por último, el colectivo de inmigrantes económicos de origen asiático y africano suman la cifra más numerosa de ilegales que, empujados por las precarias condiciones de vida en sus países de origen, buscan trabajo en España, aunque este sea mal remunerado, a fin de poder garantizar su supervivencia. Las zonas rurales y urbanas son las metas preferidas por ellos: en el primer caso se emplean en la actividad agrícola de manera estacional, mientras, en el caso de las áreas urbanas, pueden encontrar empleo en los sectores de la construcción y de los servicios.

\subsection{Estado actual de las migraciones provenientes desde el Magreb}

Como ya se ha comentado, los residentes extranjeros en España con nacionalidades de Europa Occidental constituyen, en la actualidad, el contingente más numeroso. De hecho, si hasta 1990 predominaban los inmigrantes llegados desde la Comunidad Europea, a partir de 1992 estos son menos de la mitad: a 31 de diciembre de 1996 se contabilizaron 251.919 es decir, el 46,7\% del total (cuadro 1).

En el último decenio la inmigración con mayor incremento ha sido la africana (8.529 en 1985 y 98.820 residentes en 1996), que ha crecido con una tasa anual del $24,9 \%$; en el último año, los inmigrantes africanos igualan a los latinoamericanos tradicionalmente mucho más numerosos.

Los asiáticos, los europeos y los americanos han aumentado igualmente en cifras absolutas, pero su incremento global no ha tenido la misma incidencia sobre el volumen total de los extranjeros, siendo la variación anual igual al 6,0\%, o sea, cuatro veces inferior a la africana.

El análisis sobre la presencia relativa de los africanos en España evidencia que son sobre todo los provenientes desde Magreb los que han experimentado un incremento más rápido y continuo, caracterizado por una tasa de crecimiento anual siempre superior al total de los residentes extranjeros (cuadro 2).

En 1996 se contabilizaron en España 81.305 magrebíes, es decir, el 15\% de la población extranjera total, un porcentaje muy bajo si lo comparamos al de los originarios de la Comunidad Europea, pero significativo si se piensa que esta comunidad ha tenido un incremento con respecto a 1985 de 75.037 personas. El incremento de los magrebíes se ha reforzado con ocasión de los procesos de regularización de 1985, 1991 y 1996, los cuales 


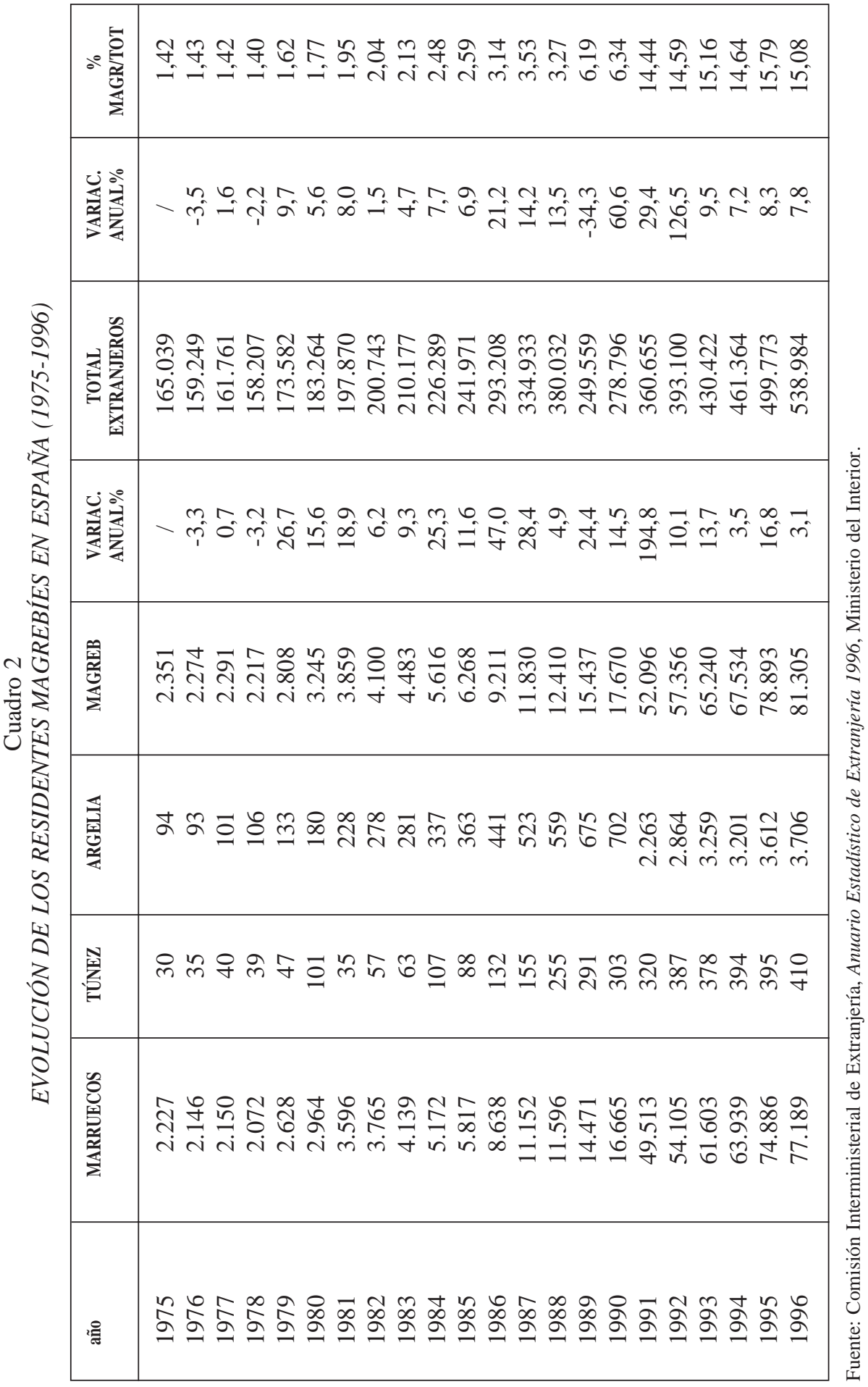


Cuadro 3

EVOLUCIÓN DEL CONTINGENTE DE MAGREBÍES CON PERMISO DE TRABAJO EN ESPAÑA (1990-1996)

\begin{tabular}{|l|c|c|c|c|}
\hline Ã̃NO & MARRUECOS & ARGELIA & TÚNEZ & MAGREB \\
\hline 1990 & 8.844 & 245 & 81 & 9.170 \\
1991 & 41.095 & 1.937 & 212 & 43.244 \\
1992 & 52.501 & 2.877 & 237 & 55.615 \\
1993 & 42.193 & 2.086 & 153 & 44.432 \\
1994 & 44.958 & 1.975 & 157 & 47.090 \\
1995 & 51.353 & 2.591 & 149 & 54.093 \\
$1996 *$ & 59.167 & 3.149 & 191 & 62.507 \\
\hline
\end{tabular}

(*) Datos provisionales Anuario Estadístico de Extranjería 1996, Comisión Interministerial de Extranjería, Ministerio del Interior.

Fuente: Datos hasta 1995, Anuario de Migraciones 1996, Dirección General de Migraciones.

han sido aprovechados para legalizar su presencia en el país, pues esta era normalmente de tipo clandestino.

En 1991 solicitaron regularización 61.679 trabajadores magrebíes y les fue concedida a 51.476 de éstos (47\% de los 108.321 demandas concedidas de un total de 130.406 presentadas); este fue el mayor aumento en los residentes marroquíes y argelinos, mientras los tunecinos crecen menos, confirmando el exiguo número de ilegales de esta nacionalidad.

Se debe observar que a partir de 1991, los magrebíes constituyen la comunidad de extranjeros con mayor número de permisos de trabajo: se pasa de 9.170 en 1990 a 62.507 trabajadores con permiso en vigor a 31 de diciembre de 1996, cifra que corresponde al 39\% del total de trabajadores extranjeros en España (161.900) y al 74\% del número total de residentes legales magrebíes (cuadro 3).

En 1996 la aprobación del nuevo Reglamento de ejecución de la Ley Orgánica 7/1985 — Ley de Extranjería - se ha traducido en una tercera regularización extraordinaria con 25.388 solicitudes, de las cuales el $40 \%$ han sido presentadas por los maghrebíes ${ }^{2}$.

Además, según las resoluciones anuales que han establecido la determinación de «cuotas» de autorizaciones para trabajadores extranjeros, desde 1993 a 1995 se han regularizado 50.770 trabajadores extranjeros, de los cuales el 36\% son magrebíes (18.391) ${ }^{3}$. Lo analizado, no hace más que confirmar el «carácter económico» de la inmigración magrebí en España.

Por otra parte, no debemos olvidar el número de naturalizados, que aunque jurídicamente son ciudadanos españoles, conservan su condición social de inmigrantes. Según las cifras dadas por la Comisión Interministerial de Extranjería, desde 1960 a 1996 han adquirido la nacionalidad española 19.774 magrebíes, así que, sobre la base de estos

2 Datos publicados en el Anuario de Migraciones de 1996, editado por el Ministerio de Trabajo y Asuntos Sociales.

3 Ministerio de Trabajo y Asuntos Sociales, Anuario de Migraciones 1996. Del análisis del «Plan de Ordenación Laboral de Flujos Migratorios» de noviembre de 1997 editado por la Dirección General de Migraciones, se observa que se han presentado 62.000 solicitudes para obtener permisos de trabajo dentro de la política de Contingente 97 , siendo el cupo total para ese año de 24.690 autorizaciones. 


\section{Cuadro 4}

INMIGRADOS MAGREBÍES QUE HAN OBTENIDO LA CIUDADANÍA ESPAÑOLA

DURANTE 1960-1996

\begin{tabular}{|l|c|c|r|r|}
\hline AÑOS & MARRUECOS & ARGELIA & TÚNEZ & MAGREB \\
\hline $1960-1965$ & 77 & 1 & $/$ & 78 \\
$1966-1975$ & 252 & 14 & $/$ & 266 \\
$1976-1985$ & 1.232 & 50 & 20 & 1.302 \\
$1986-1996$ & 17.809 & 219 & 70 & 18.098 \\
\hline TOTAL & 19.370 & 284 & 90 & 19.744 \\
\hline
\end{tabular}

Fuente: Datos hasta 1995, Anuario de migraciones 1996, Dirección General de Migraciones.

Datos de 1996, Anuario Estadístico de Extranjería 1996, Comisión Interministerial de Extranjería.

nuevos datos, la inmigración proveniente del Magreb estaría compuesta por más de 100.000 individuos entre residentes y naturalizados españoles (cuadro 4$)^{4}$.

Lo que determina el movimiento migratorio de la población del Norte de África, son esencialmente los factores demográficos y económicos. En lo que concierne a los primeros, hay que tener en cuenta que en el Magreb se espera entre 1990 y el 2025 un incremento demográfico aproximado de 54 millones de personas, incremento que interesará de manera particular a la población magrebí en edad activa, la cual constituirá, según las previsiones, el $56 \%$ del total en el $2025^{5}$. Esto significa que en ausencia de un adecuado crecimiento económico dirigido a satisfacer una fuerte necesidad ocupacional, los países del área magrebí no podrán renunciar a la válvula migratoria hacia los estados de la Europa mediterránea, que demográficamente se encuentran «estancados» a causa de su baja tasa de natalidad y con una población envejecida, lo que puede requerir inmigrantes al menos para atender el mercado de trabajo secundario, no atractivo para la población local. A la luz de estas consideraciones, los factores económicos que activan los flujos migratorios desde África del Norte hacia España, responden singularmente a un excedente de mano de obra que no encuentra empleo en su país de origen. De hecho, los inmigrantes magrebíes que atraviesan la frontera marítima a bordo de embarcaciones ligeras, llegan a las playas de las provincias de Cádiz, Almería y Málaga la mayor parte como clandestinos o «turistas»; las provincias del litoral Mediterráneo de Cádiz a Girona son sus metas preferidas, pues aquí pueden encontrar trabajos temporales u ocasionales en el sector agrícola.

Por otra parte, de la observación de los datos suministrados por el Anuario Estadístico de Extranjería de 1997 relativos a la presencia de los trabajadores magrebíes con permiso de trabajo en vigor, se deduce que en las Comunidades Autónomas de Cataluña, Comunidad Valenciana, Andalucía, Murcia y Madrid hay dos maghrebíes de cada tres censados en España: 62.277 Marroquíes (63\% del total residente), 2.663 Argelinos (72\% del total) y 334 Tunecinos ( $81 \%$ del total).

4 Los naturalizados no son objeto de análisis en este trabajo, debido a que merecerían la realización de otra investigación; de todas maneras, estos deben ser mencionados, ya que resulta un dato significativo en el ámbito del estudio de la integración social de los inmigrantes.

5 MORETTI, E. (1996): «Il Maghreb e l'Europa: quali possibili politiche migratorie?» Quaderno 9, Universitá degli Studi di Bari, Dipartimento per lo Studio delle Societá Mediterranee, Cacucci Editore, Bari. 
La distribución por sectores de actividad cambia según las nacionalidades, aunque en general se nota una fuerte presencia magrebí en el sector de servicios y en agricultura.

En definitiva, la comunidad magrebí representa en España sólo el 0,5\% de la población total (40 millones de habitantes), un porcentaje insignificante que no está relacionado a nivel de cifras con el «peligro magrebí» convertido en el slogan de un nuevo «populismo» europeo. Sin embargo esta presencia extranjera está destinada a crecer a falta de una serie de medidas que lleven a equilibrar la disparidad entre niveles de vida decadentes de las poblaciones en aumento, de un lado, y la opulencia creciente de las poblaciones estacionarias, de otro lado.

España y Magreb, aunque cercanas geográficamente, se colocan económicamente en lados opuestos: el primero, aunque se encuentra en el sur de Europa, debe considerarse como parte de un Norte que detenta el $87 \%$ de la riqueza mundial, el segundo pertenece a un Sur que debe sobrevivir con el otro $13 \%$, por lo que se ve obligado a expulsar a parte de su población para buscar una vida mejor en otro lugar.

\section{Andalucía, nueva área de acogida de los trabajadores marroquíes}

\subsection{Una mirada a los rasgos políticos y económicos del Marruecos independiente}

Situado en el extremo noroeste del continente africano, considerado «ventana» sobre Europa del mundo árabe-musulmán, Marruecos desde siempre ha capitalizado un fuerte ascendiente sobre los estados limítrofes por su posición geográfica estratégica.

En el transcurso de su historia, este país ha recibido diversas influencias que las poblaciones han asimilado, mientras ha conservado fidelidad al Estado central (Makner), a su vez consolidado por las dinastías que se han sucedido en su gestión. El fuerte sentimiento nacional, no obstante las diversidades étnicas, linguísticas y religiosas, y la cohesión de su población, han permitido a Marruecos preservar siempre la propia autonomía, e incluso se sustrajo al dominio turco del Imperio Otomano, inevitable por sus otros Estados vecinos del Magreb. Tampoco el medio siglo de dominación franco-española ha privado a Marruecos de su personalidad histórico-política, sino que al contrario le ha garantizado «una independencia en la interdependencia» presentándose bajo la forma política de Protectorado, en el que el sultán Mohamed V resultaba jurídicamente el único soberano del país. Actualmente Marruecos es una monarquía constitucional conducida por un rey garante de los derechos y de las libertades de los ciudadanos, de los grupos sociales y que vigila por el respeto de la Constitución y del Islam en cuanto religión del Estado.

La historia política reciente de Marruecos, iniciada con la independencia y la redacción de la primera constitución en 1962, resume una serie de batallas electorales, acuerdos y compromisos entre los partidos de la derecha y el centro, ligados a las tradiciones y sostenidos por los electores de los centros rurales, mientras los partidos de la izquierda progresista son apoyados por los electores de los centros urbanos.

En el año en curso, después de cincuenta años de absoluta gestión del país por parte de una derecha centralizada, unida en alianza con el centro en la formación «Entente National», se debe destacar un hecho sin precedentes en la historia de Marruecos, el nombramiento como jefe de gobierno del socialista Youssofí (4 de febrero de 1998), del Partido Union Socialiste des Forces Populaires (USFP), después de la victoria en las elecciones legislativas de noviembre de 1997. Se trata de una designación que «a accompagné la liberation puis l'edification d'un etat indépendent ${ }^{6}$ marcando el inicio de una alternancia

6 Abdelladif Monsour, «Itineraire accompli d'un miltant», Maroc Hebdo International, N ${ }^{\circ} 309,7-13$ fevrier 1998 . 
política que surgió en 1992 con el pronunciamiento del Rey Hassan II a favor del multipartidismo.

En lo que se refiere a la historia de los hechos económicos de este país, se observa que a partir de 1956, año de la independencia política del Reino de Marruecos, el gobierno ha optado por una economía liberal. De hecho, el modelo económico marroquí se ha mostrado deficiente ya desde finales de los años 70 con la exasperación del desequilibrio financiero interno y externo, agravado por la caída de los precios del fosfato en 1976 y del segundo shock petrolífero de 1979, por lo que el recurso a planes de reforma económica finalizados para sanear el déficit público deviene una etapa obligada. En particular, en 1983 Marruecos aprobó un Plan de Ajuste Estructural con el sostén del Fondo Monetario Internacional y del Banco Mundial que, si sobre el plano de los equilibrios macroeconómicos ha conseguido importantes resultados como el descenso de la tasa de inflación y del déficit nacional, sobre el plano más exquisitamente social, se ha enfrentado con una población exhausta al sostener un crecimiento nacional basado esencialmente en la reducción de la parte de las inversiones públicas en las inversiones globales (34\% en 1982 y $2 \%$ en 1992).

A la luz de lo dicho, consciente de la importancia del sostén de la opinión pública, el Estado ha tenido que reorientar los programas de la gestión económica a beneficio del interés de las partes sociales, animando inversiones para crear empleo sobre todo en las zonas rurales (ámbito en el que aún hoy vive el $47 \%$ de la población total).

En cuanto al cuadro económico contemporáneo de Marruecos, si se contemplan los indicadores como su elevada tasa de desempleo del $18 \%$ en diciembre de 1996, la fuerte deuda exterior de 22.100 millones de dólares equivalente al 68\% del PIB anual, la débil actividad industrial (58\% de los productos manufacturados son importados), en la que trabaja sólo el $26.6 \%$ de los activos, se comprenden unas importantes variantes que determinan el «push» de esta tierra hacia metas económicamente más rentables.

Así, se puede afirmar que la movilidad de los marroquíes hacia los países más desarrollados, sobre todo de la UE, no puede considerarse ajena a la evolución económica, política y social del país.

\subsection{Orígenes y evolución de la inmigración marroquí en España}

En su relación con Marruecos, España se presenta como la frontera meridional de la UE y como el país del norte más vecino. Separados por una lengua de mar de sólo $17 \mathrm{Km}$, estos dos países son legados de una historia común pasada y reciente, favorecida por una constante y recíproca compenetración entre sus culturas y los diferentes modos de vida. En este último siglo, los años del Protectorado Español sobre Marruecos (1912-1956) marcan una fase importante de esta relación, después caracterizada por la infiltración española sobre el territorio africano a través de las ciudades de Ceuta y Melilla. En los años 60 ha habido una inversión de tendencia con una primera inmigración marroquí hacia España proveniente de los «mellah» (juderías) de Tetuán, Tánger y Nador. Un flujo configurado como un éxodo de familias marroquíes de confesión judía que se instalan en su mayoría en las ciudades de Madrid y Barcelona entre 1956 y 1964, fecha a partir de la cual el movimiento migratorio se detuvo hasta intensificarse nuevamente en $19677^{7}$.

En los inicios de los años 70, el cierre de las fronteras de algunos países de Europa Occcidental, en otros tiempos receptores de mano de obra, ha determinado el incremento

7 MARTÍN LISBONA, J.A. (1996): «La especificidad de las migraciones judías de Marruecos a España (1956-1970)» Atlas de la inmigración magrebí en España, Universidad Autónoma de Madrid y Ministerio de Asuntos Sociales. 
de la instalación definitiva de marroquíes sobre el territorio español. En esta segunda fase, los que se desplazan son en su mayoría hombres en edad activa y con un elevado índice de analfabetismo, originarios de las zonas agrícolas más pobres de dos regiones al norte de la nación: el Rif, formado por las provincias de Nador y Al-Hoceima y Yabala con Tetuán, Tánger, Khaouen y Larache.

Por último, la gran oleada de marroquíes datada a principios de los años 80 se distingue de la precedente por el elevadísimo número de clandestinos y por la presencia conjunta en el colectivo de una población de origen rural (proveniente siempre del centro del ex Protectorado español o sea del Rif) y de una población de origen urbano de las grandes ciudades del antiguo protectorado francés es decir Casablanca, Rabat, Kenitra y Fez.

Actualmente, los marroquíes en España constituyen la comunidad extranjera más numerosa - 77.189 residentes legales el 31 de diciembre de 1996 - seguidos por los británicos (68.359) y los alemanes (45.898); en el período de 1985 a 1996 el contingente marroquí ha aumentado con una tasa de crecimiento anual del 26,2\%.

Aunque la presencia marroquí en España resulte significativa desde inicios de los años 80 , se debe tener en cuenta que el stock de los residentes marroquíes ha crecido rápidamente, emergiendo en las estadísticas oficiales sólo después de los dos procesos de regularización de los extranjeros en situación ilegal. Con ocasión del primero, realizado entre julio del 85 y marzo del 86, los marroquíes presentaron 7.868 demandas de regularización (sobre un total de 43.815) de las cuales 5.815 fueron aceptadas; con la regularización de los trabajadores extranjeros de 1991 realizada durante el período junio-diciembre del mismo año y concluida en 1992 para las familias de los mismos, los marroquíes que intentaron regularizar su situación fueron 57.753, de los que fueron aprobados 48.240 solicitudes o sea el $83.5 \%$ de las presentadas por los marroquíes, que a su vez representan el $44.5 \%$ de las 108.321 resueltas favorablemente en total absoluto ${ }^{8}$.

Tanto de la primera como de la segunda regularización se deriva una fuerte crecida del número de los residentes marroquíes, que de 5.817 en 1985 pasaron a ser 11.596 en 1987 (aumento del 99.3\%), y de 49.513 en 1991 a 61.603 en 1993 (aumento del 24.4\%) (cuadro 2).

En el período de abril-agosto de 1996, como se ha dicho anteriormente, una nueva regularización ha tenido lugar en España con ocasión del nuevo Reglamento de Ejecución de la Ley de Extranjería de 1985; según datos oficiales hasta el 11 de noviembre de 1996, se habían presentado 25.388 solicitudes de regularización.

Del análisis de un Informe de Gestión de 30 de julio de 1997, redactado por la Dirección General de Migraciones, se revela que en 1996 fueron presentadas 17.676 solicitudes en el Ministerio de Trabajo y Asuntos Sociales para obtener el permiso de residencia y de trabajo. De éstas, 14.065 han sido aceptadas; Marruecos con 4.895 se confirma como el país más representativo de solicitudes resueltas favorablemente.

Por otra parte, no se puede olvidar la Resolución adoptada por el gobierno el 14 de junio de 1993 a propósito de la «política de los contingentes» con vistas a ubicar a «los inmigrantes económicos» en ciertos sectores laborales en función de la necesidad de mano de obra en la economía española. Consecuencia de esta medida, en 1993, 1994 y 1995 han sido concedidas 46.881 autorizaciones de empleo a extranjeros. En este ámbito, de nuevo dominan los marroquíes con 18.629 autorizaciones obtenidas, mientras se esperan los datos inherentes a las solicitudes presentadas para 1997, año en el que ha sido fijado un cupo de 24.600 permisos.

8 Dirección General de Migraciones, Anuario de Migraciones 1996, Madrid, Ministerio de Trabajo y Asuntos Sociales. 
CUADRO 5

EVOLUCIÓN DEL STOCK DE TRABAJADORES MARROQUÍES EN ESPAÑA CON

PERMISO DE TRABAJO EN VIGOR DE 1990 A 1996

\begin{tabular}{|c|c|c|c|c|c|c|}
\hline & 1990 & 1991 & 1993 & 1994 & 1995 & $1996^{*}$ \\
\hline \multicolumn{7}{|l|}{ SEXO } \\
\hline masculino & 7.269 & 34.090 & 35.820 & 37.006 & 43.491 & 49.502 \\
\hline femenino & 1.421 & 7.005 & 6.373 & 6.723 & 7.862 & 9.665 \\
\hline \multicolumn{7}{|l|}{ RÉGIMEN LABORAL } \\
\hline c. ajena & 6.306 & 35.836 & 36.387 & 38.027 & 45.838 & 53.391 \\
\hline c. propia & 2.384 & 5.259 & 5.806 & 5.702 & 5.515 & 5.776 \\
\hline \multicolumn{7}{|l|}{ SECTOR DE ACTIVIDAD } \\
\hline agrario & 944 & 10.016 & 10.416 & 10.140 & 15.430 & 19.387 \\
\hline servicios & 5.235 & 18.006 & 17.040 & 16.316 & 18.921 & 21.357 \\
\hline industria & 640 & 3.208 & 3.984 & 3.676 & 4.263 & 4.683 \\
\hline construcción & 1.824 & 9.660 & 9.156 & 7.272 & 8.351 & 9.063 \\
\hline TOTAL TRABAJADORES & 8.690 & 41.095 & 42.193 & 43.729 & 51.353 & 59.167 \\
\hline
\end{tabular}

Fuente: Anuario de Migraciones (1992, 1993, 1994, 1995), Madrid, Dirección General de Migraciones, Ministerio de Trabajo y Asuntos Sociales. Datos de 1996, Anuario Estadístico de Extranjería 1996, Comisión Internacional de Extranjería.

*Datos provisionales.

En realidad, el cuadro hasta ahora delineado no se puede considerar satisfactorio: el dato más interesante en el estudio de la presencia marroquí en España se refiere al stock de trabajadores de esta nacionalidad. En 1995 fueron 51.353 los marroquíes que trabajaban en este país con permiso en vigor el 31 de diciembre de ese año (66,5\% del total de trabajadores extranjeros), seguidos de los sudamericanos, en concreto peruanos (11.368), dominicanos (9.737) y argentinos (7.526). Después de la regularización de 1991, el número de trabajadores marroquíes ha aumentado rápidamente, multiplicándose por 5,9 de 1990 a 1992, es decir pasan de 8.844 a 52.501 con una tasa de crecimiento absoluto del $493 \%$ (cuadro 3).

La observación de los datos disponibles en 1996 permite individualizar ciertas características peculiares de los trabajadores marroquíes en España: 1) se trata fundamentalmente de hombres (49.502 o sea el 83,7\%) de 25 a 50 años; 2) 53.391 de éstos $(90,2 \%)$ trabajan por cuenta ajena mientras sólo 5.776 trabajan por cuenta propia; 3) la mayoría se concentra en el sector servicios (21.357, es decir el 36,1\%) y en el sector agrícola (19.387, el 32,8\%) mientras la presencia de los marroquíes en el sector de la construcción y de la industria confirma porcentajes bajos, el 5,3\% y el 7,9\%, respectivamente (cuadro 5).

Estas cifras llaman nuestra atención porque se enfrentan con la realidad de los otros países europeos que, sobre todo en los años 60, utilizaron la mano de obra extranjera en el sector industrial. En esencia, la elección del sector servicios y agrícola por parte de los trabajadores marroquíes es el resultado de su adaptabilidad a las necesidades del momento y a las nuevas reglas del mercado laboral. En nuestros días, la economía española ofrece ciertas oportunidades sólo a la mano de obra que demuestra «flexibilidad», entendida como capacidad de aceptar duras condiciones de trabajo y bajo salario, todo en nombre de la 
provisionalidad. Un alto precio que los españoles están menos dispuestos a pagar a cambio de empleos por otra parte poco cualificados. Obviamente, como ya hemos visto, la consecuencia es la fuerte concentración de marroquíes en los sectores de servicios y agrícola. Esto último en los años más recientes sobrevive y crece gracias a ellos, que al mismo tiempo utilizan las actividades agrícolas estacionales como «bolsa de trabajo»" primer paso para la inserción en otros ámbitos laborales con mejores retribuciones y garantías.

Las conclusiones surgen solas: el inmigrante marroquí no puede definirse como refugiado político ni tampoco como refugiado ecológico, aunque Marruecos reúne en sí mismo una tipología de problemas relacionados con el medio ambiente y la vida política que a su vez son motivos de empuje para ciertas franjas de la población. Sin duda, son las razones socioeconómicas las que impulsan a los marroquíes hacia España. A estas variables, necesarias pero no suficientes, hay que añadir la proximidad geográfica entre Marruecos y España, el pasaje relativamente sencillo del Estrecho de Gibraltar y la frontera terrestre común representada por las ciudades de Ceuta y Melilla. Además hay que contabilizar la posibilidad de recurrir y de ser acogidos por una vasta red de parientes, amigos y conocidos ya establecidos en España, que permiten neutralizar la distancia de la madre patria.

Quedan cuestiones a plantearse: ¿por qué «verdaderamente» cada año miles de marroquíes dejan su casa y sus vínculos afectivos para alcanzar nuevos países? Si el atractivo económico es tan importante y la tierra soñada es tan cercana, ¿por qué «mille hésitations devant à un coup de ciseaux»? Quien escribe querría verse satisfecha con los tópicos comunes, pero ¡no «puede» hacerlo!

\subsection{Algunos datos sobre la clandestinidad de los inmigrantes marroquíes en España}

Aunque en los últimos años se ha fortalecido el control de las fronteras externas de la Unión Europea mediante la adopción de medidas que incluyen la obligatoriedad de visados para numerosos países terceros ${ }^{10}$, el flujo de los inmigrantes magrebíes hacia este continente no ha disminuido. En algunos estados, al contrario de lo que se esperaba, estas nuevas disposiciones jurídicas han favorecido el aumento de la clandestinidad, característica peculiar de los marroquíes en España. En realidad, los inmigrantes de esta nacionalidad encuentran empleo en los sectores con fuerte «flexibilidad laboral» que, como anteriormente se ha indicado, no necesitan trabajadores con empleo fijo.

Obviamente, la posibilidad de cuantificar el fenómeno de la clandestinidad no es posible por diversas dificultades, entre ellas las condiciones en que trabajan estos inmigrantes, es decir su discontinuidad y su movilidad geográfica. No obstante, si se evalúa la problemática en un contexto más amplio, se reconoce que en España las regularizaciones de los extranjeros de 1985 y 1991 han permitido visualizar a nivel de cifras su presencia irregular. A su vez, dichos procesos también han permitido el estudio del aspecto ligado a la «reclandestinidad» ${ }^{11}$, que es consecuencia del problema de los permisos no renovados.

Por lo que se refiere a los marroquíes, en el proceso de regularización de 1991 presentaron 57.753 solicitudes de las cuales fueron denegadas 9.523 , es decir el $16.4 \%$. Al año

9 GOZÁLVEZ PÉREZ, V., LÓPEZ TRIGAL, L. (1998): «Jornaleros extranjeros en el campo español», Ería (en prensa).

10 España se ha adherido al «Acuerdo de Schengen» en 1991 que confirma la libre circulación de las personas en el interior de este espacio e invita a la adopción de normas y disposiciones homogéneas para reglamentar el control en las fronteras. Con este propósito España, en el ámbito de su política migratoria, ha impuesto la obligación de visados para los ciudadanos del Magreb a partir de mayo 1991.

11 COHEN, A. (1995): «Algunas reflexiones a propósito de la inmigración magrebí en España», Ería, $\mathrm{n}^{\circ} 38$. 


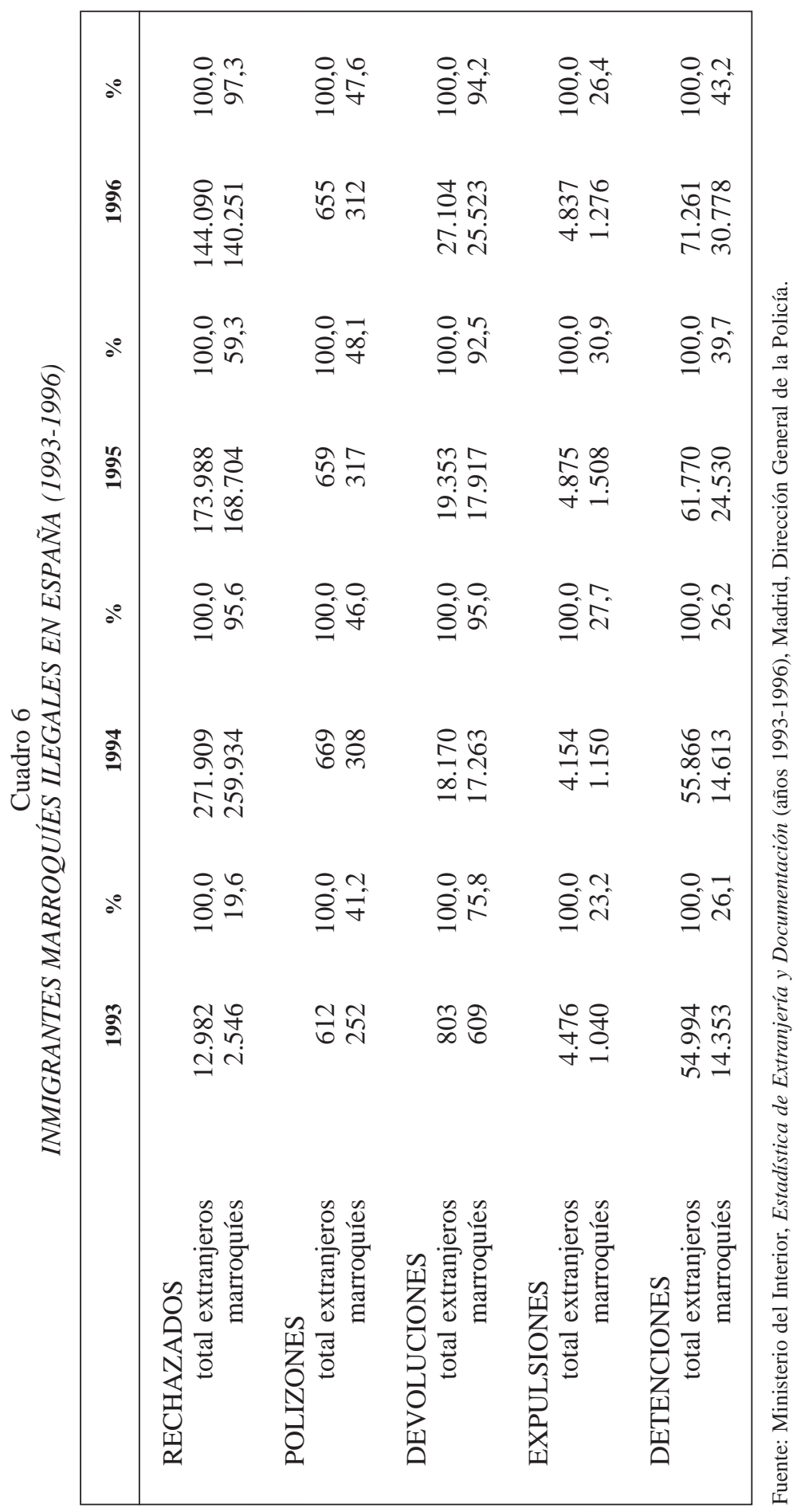


siguiente las demandas de renovación de los permisos fueron 42.145 de las cuales 3.237 fueron denegadas ${ }^{12}$, es decir el $7.7 \%$. Llegamos, pues, a un punto importante: en 1992, 18.845 trabajadores marroquíes regularizados el año anterior no se presentaron en la fecha de la renovación por motivos desconocidos, o se les rechazó la renovación, por lo que seguramente volvieron a la irregularidad. En segundo lugar, los permisos denegados con ocasión de la regularización de 1991, que fueron 9.523 sin duda continuaron en España como «bolsa» de irregulares no resuelta. Naturalmente este análisis se refiere al período inmediatamente posterior a la regularización de 1991 y sirve, sobre todo, para evidenciar como ya las primeras políticas migratorias intentaron solucionar jurídicamente la problemática de la clandestinidad aunque sin llegar a conseguirlo totalmente.

Para reflejar la inmigración irregular en España en los años más recientes puede ser útil hacer referencia a los datos ofrecidos por la publicación «Estadística de Extranjería», redactada por la Dirección General de la Policía, relativos a los siguientes indicadores: 1) polizones; 2) rechazados; 3) devueltos; 4) expulsados; 5) detenidos.

Se debe tener en cuenta que, mientras los dos primeros indicadores suministran cifras relativas a los inmigrantes ilegales inmediatamente reconocidos como tales en la frontera, los otros indicadores identifican a los extranjeros que tras una residencia irregular en España, han sido descubiertos por la policía.

En 1996, los marroquíes rechazados en la frontera fueron 140.251 (97.3\% de los 144.090 en total), mientras que los polizones de dicha nacionalidad fueron 312 (45,2\% de los 1.996 en total). En este año fueron devueltos 25.523 marroquíes, fueron expulsados 1.276 y 30.778 fueron detenidos por motivos diversos pero entre los que figura la residencia o el trabajo ilegal (cuadro 6). El estudio de la evolución de estos indicadores demuestra que los movimientos ilegales no se han detenido durante los últimos años. Es más, entre 1993 y 1996 el número de marroquíes devueltos y detenidos ha aumentado. Análogamente, el dato de 1994 relativo a los marroquíes rechazados en la frontera evidencia un incremento de 257.388 individuos con respecto a 1993, mientras se observa una flexión del mismo indicador en los años 1995-1996, aunque se mantiene mayoritario el porcentaje de los marroquíes sobre el total de los inmigrantes rechazados. El quid de la cuestión es intuitivo: los incrementos de dichos indicadores se pueden considerar, sin duda, emblema de la revitalización de los controles en la frontera tras la entrada en vigor del Acuerdo Schengen. Así pues, si cuanto se ha dicho es válido, las estadísticas prueban que los inmigrantes marroquíes no han dejado de entrar clandestinamente en España. Las cifras a disposición hablan claro: ¡todavía hoy, no obstante el servicio de policía en la frontera meridional de España (es decir, en Ceuta y Melilla) y en las estaciones marítimas de mayor tránsito en el norte del Estrecho de Gibraltar (es decir, en los puertos de Cádiz, Algeciras y Málaga), se encuentra una fuerte presencia de inmigrantes irregulares sobre el territorio español.

\subsection{Características generales de los inmigrantes marroquíes en Andalucía}

En la España de los pueblos y de las culturas diferentes, Andalucía es sin duda la comunidad autónoma que mejor se presta al encuentro entre Europa y el Norte de África. La más meridional de las regiones de la Unión Europea aún hoy sobrepasa la frontera natural del Atlántico y del Mediterráneo para dominar en una parte del mundo árabe con «sus plazas de soberanía» (las ciudades de Ceuta y Melilla).

12 IZQUIERDO ESCRIBANO, A. (1996): La Inmigración inesperada. Editorial Trotta, Madrid. 


\section{Cuadro 7}

RESIDENTES EN ESPAÑA DE NACIONALIDAD MARROQUÍ, ARGELINA Y

TUNECINA; COMUNIDADES AUTÓNOMAS CON MAYOR PRESENCIA

MAGREBÍ (A 31-12-1996)

\begin{tabular}{|l|rrrr|}
\hline COMUNIDADES AUTÓNOMAS & MARRUECOS & ARGELIA & TÚNEZ & MAGREB \\
\hline ANDALUCÍA & 10.548 & 411 & 53 & 11.012 \\
CATALUÑA & 29.459 & 707 & 125 & 30.291 \\
COMUN. VALENCIANA & 4.313 & 1.036 & 36 & 5.385 \\
MADRID & 14.194 & 360 & 112 & 14.666 \\
MURCIA & 3.763 & 149 & 8 & 3.920 \\
\hline TOTAL & 62.277 & 2.663 & 334 & 65.274 \\
\hline
\end{tabular}

Fuente: Comisión Interministerial de Extranjería, Anuario Estadístico de Extranjería 1996, Ministerio del Interior

En lo que atañe a la evolución y las tendencias de su población, es necesario recordar que esta región ha sufrido durante años la pérdida de muchos jóvenes en edad activa, pues la emigración ha jugado un rol decisivo en su historia reciente.

El saldo migratorio andaluz fue negativo sobre todo en el período 1950-1970 cuando alcanzó la cifra de 1.427 .393 emigrantes tras el gran flujo continental y transoceánico e interregional, es decir, orientado hacia las comunidades autónomas más desarrolladas de España. Hasta 1950 el contingente migratorio andaluz generó un movimiento interno desde los centros rurales de Andalucía Oriental hacia los centros urbanos favoreciendo el crecimiento de sus capitales como Granada, Sevilla y Málaga. Posteriormente, de 1950 a 1970, los andaluces se dirigieron primero hacia Cataluña, Madrid, las Baleares y el litoral valenciano y después hacia Europa occidental, llevando a Andalucía al primer lugar entre las regiones españolas de mayor empuje emigratorio ${ }^{13}$.

Como acaeció en todos los países europeos de emigración, la crisis petrolera de 1973 marcó un turn over en el panorama nacional, de tal manera que se redujo la movilidad de la población andaluza hacia el extranjero (los emigrantes andaluces pasaron de ser 144.455 entre 1971-1975 a 14.455 entre 1976-1980) ${ }^{14}$. Además, al principio de los años ' 80 empezó un intenso y progresivo movimiento de retorno de la mano de obra desplazada con anterioridad.

Por contra, durante los años 90, Andalucía se transforma en una nueva área de acogida para los trabajadores extranjeros, en su mayor parte originarios del Magreb.

A 31 de diciembre de 1996, Andalucía es la tercera comunidad autónoma española en número de extranjeros residentes, con 70.725 , que representan el $13.1 \%$ de la población extranjera total residente en España y el 1.1\% de la población andaluza censada en 1991. En definitiva, si en ciertos aspectos esta región ha permitido siempre el tránsito de las poblaciones africanas hacia los estados europeos, desde 1985 también ha devenido meta de sus duros viajes. Se trata de los años de la llamada «tercera oleada marroquí», en los que la

13 CAZORLA PÉREZ, J.; MONABES PEREIRA, J. (1996): «Andalucía en la encrucijada de ida y vuelta», Atlas de la inmigración magrebi en España, Universidad Autónoma de Madrid.

14 Dirección General de Migraciones, Anuario des Migraciones 1996, Ministerio de Trabajo y Asuntos Sociales, Madrid. 
Cuadro 8

RESIDENTES MARROQUÍES EN ANDALUCÍA (1993-1996).

DISTRIBUCIÓN POR PROVINCIAS

\begin{tabular}{|l|rrrr|rrrr|r|}
\hline \multirow{2}{*}{ ANDALUCÍA } & \multicolumn{5}{|c|}{ CIFRAS ABSOLUTAS } & \multicolumn{3}{c|}{ \% } & VARIACIÓN \% \\
& $\mathbf{1 9 9 3}$ & $\mathbf{1 9 9 4}$ & $\mathbf{1 9 9 5}$ & $\mathbf{1 9 9 6}$ & $\mathbf{1 9 9 3}$ & $\mathbf{1 9 9 4}$ & $\mathbf{1 9 9 5}$ & $\mathbf{1 9 9 6}$ & $\mathbf{1 9 9 3 - 1 9 9 6}$ \\
\hline Almería & 1.773 & 2.033 & 3.002 & 3.081 & 18,8 & 21,1 & 26,9 & 29,2 & 18,0 \\
Cádiz & 1.576 & 1.415 & 1.356 & 1.442 & 16,7 & 14,7 & 12,1 & 13,7 & $-2,6$ \\
Córdoba & 287 & 335 & 366 & 357 & 3,0 & 3,5 & 3,3 & 3,4 & 6,8 \\
Granada & 1.581 & 1.433 & 1.641 & 865 & 16,7 & 14,8 & 14,7 & 8,2 & $-16,6$ \\
Huelva & 179 & 537 & 621 & 747 & 1,9 & 5,6 & 5,6 & 7,1 & 53,5 \\
Jaén & 447 & 332 & 377 & 389 & 4,7 & 3,4 & 3,4 & 3,7 & $-4,1$ \\
Málaga & 2.862 & 2.868 & 2.958 & 2.844 & 30,3 & 29,7 & 30,7 & 27,3 & $-0,2$ \\
Sevilla & 730 & 694 & 808 & 823 & 7,7 & 7,2 & 7,3 & 7,8 & 3,7 \\
\hline TOTAL & 9.435 & 9.647 & 11.129 & 10.548 & 100 & 100 & 100 & 100 & 3,4 \\
\hline
\end{tabular}

Fuente: Datos de 1993 a 1995, Anuario de migraciones, Madrid, Dirección General de Migraciones, Ministerio de Trabajo y Asuntos Sociales.

Datos de 1996, Anuario Estadístico de Extranjería, Madrid, Comisión Interministerial de Extranjería, Ministerio del Interior.

presencia de los inmigrantes de esta nacionalidad llega a ser significativa y coincide con su instalación en las ciudades y campos andaluces. Esta instalación se hace patente con la regularización de 1991 y es posible sobre todo por el fuerte crecimiento económico experimentado en la costa de Almería, debido al desarrollo de los cultivos en invernadero.

En 1996 se contabilizaron en Andalucía 10.548 marroquíes (cuadro 7), es decir el 15\% de su población extranjera residente, una cifra que de 1990 a 1996 ha crecido el 170\% en cifras absolutas, aunque en 1996 se produce un decrecimiento de los marroquíes en las provincias de Granada, Málaga y Córdoba (cuadro 8). La mayor parte de los marroquíes de Andalucía residen en las provincias de Almería, Málaga, Cádiz y Granada; la provincia de Almería censa 3.081 marroquíes con permiso de residencia en vigor, de tal manera que este área - que afecta a pocos municipios - puede ser considerada un importante centro de acogida de los inmigrantes de esta nacionalidad. La proximidad geográfica de Marruecos con el litoral almeriense y la fuerte demanda de mano de obra solicitada en el sector de la agricultura intensiva en los municipios litorales son los factores de atracción hacia las localidades de la provincia. A estos factores se debe añadir las precarias condiciones económicas de las regiones de origen de los inmigrantes que determinan el empuje definitivo en el proceso de decisión migratoria. Según estudios efectuados sobre el terreno ${ }^{15}$, un elevado porcentaje de los marroquíes residentes en Almería provienen del nordeste de Marruecos (de la región del Rif, en particular de la provincia de Nador), que constituye una de las áreas menos desarrolladas del país por la inexistencia de actividad industrial y por un tipo de agricultura basada en el cultivo de cereales de escasas expectativas económicas. El litoral Atlántico con las ciudades de Casablanca, Rabat y Kenitra aportan otro contingente numeroso, es decir el de origen urbano. Actualmente, Almería es una de las provincias

15 GOZÁLVEZ PÉREZ, V. (1995) (Dir.): Inmigrantes marroquíes y senegaleses en la España Mediterránea, Generalitat Valenciana, Valencia. 
españolas menos industrializadas, por lo que los marroquíes se concentran en la zona más litoral, entre el río homónimo y el río Adra donde pueden encontrar colocación en el sector agrícola. En particular, las comarcas del Campo de Dalías y el Campo de Níjar son el principal centro de la inmigración ilegal, atraída por el trabajo que requieren los cultivos estacionales de horticultura bajo abrigo de plástico.

En lo que se refiere a la provincia de Málaga ${ }^{16}$, en 1996 censó 2.844 marroquíes en situación regular, provinientes de las grandes ciudades del litoral Atlántico de Marruecos, Casablanca y Rabat. El dato más interesante sobre esta provincia se refiere a la fuerte presencia femenina: Málaga concentra el mayor número de mujeres marroquíes en el territorio andaluz, en especial empleadas del hogar. En general, se trata de mujeres que al no estar vinculadas por matrimonio, recurren a la válvula migratoria con el fin de poder enviar remesas a los familiares que residen en su patria.

A diferencia de las dos provincias anteriores, Cádiz concentra sobre todo marroquíes de origen rural: 1.442 marroquíes residentes en este área proceden originariamente de la zona del Atlas, acompañados por sus familias. La población marroquí en Cádiz cuenta con muchos núcleos familiares que consideran a Andalucía como su tierra y no manifiestan intenciones de retorno a su país de origen. Los municipios de Jerez de la Frontera y Algeciras son los más dinámicos, donde los marroquíes ejercitan el comercio autónomo de forma ambulante o en bazares. Por otra parte, en los puertos de Algeciras y Cádiz, la pesca emplea a muchos marroquíes cumpliendo las obligaciones de los convenios sobre esta materia entre España y Marruecos, convenios que exigen una presencia proporcionada de trabajadores de esta nacionalidad en las flotas españolas.

Por último Granada, con 865 marroquíes regulares en 1996, se distingue de las otras provincias por la fuerte presencia de estudiantes universitarios árabes; según un censo de la población estudiante efectuado por la Universidad de Granada, durante el año académico de 1993-1994, alrededor de un millar de jóvenes marroquíes siguieron cursos de licenciatura y doctorado. La mayor parte de estos pagan las tasas universitarias trabajando en los campos del Llano de Zafarraya en los periodos de recolecta de tomate, espárragos y alcachofa. En realidad esta actividad agrícola estacional ocupa también a muchos marroquíes solteros en clandestinidad y en espera de regularización.

Las restantes provincias andaluzas reagrupan un número irrelevante de marroquíes con permiso en vigor, aunque el litoral de Huelva y la zona de Jaén atraen inmigrantes de tránsito, imposibles de cuantificar exactamente y obviamente ausentes en las estadísticas oficiales. Como consecuencia, gracias a la recogida de aceituna en Jaén y al cultivo de fresones en Huelva, también la Andalucía Occidental ha podido contar con un elevado contingente de inmigrantes, principalmente africanos, a partir de los años 90.

\section{Balances y perspectivas de las relaciones políticas y económicas hispano-marro- quíes}

\subsection{Tratados, acuerdos y convenios entre España y Marruecos desde 1980 a 1998}

De todas las relaciones tradicionales entre España y el mundo árabe, la más importante ha sido sin duda la mantenida entre España y Marruecos. Ésta, que históricamente ha sido

16 Las informaciones sobre la población marroquí en las provincias de Málaga, Cádiz y Granada son el resultado de un estudio realizado sobre la base de entrevistas realizadas a los inmigrantes africanos en Andalucía. Proyecto de Investigación: La integración de los inmigrantes en Andalucía, editado por la Universidad de Sevilla y patrocinado por la Consejería de Asuntos Sociales de la Junta de Andalucía. 
tormentosa, aún hoy se presenta incierta por su alternancia entre momentos de tensión y acercamiento.

Por otra parte, entre España y Marruecos persisten muchas divergencias sobre temas de particulares intereses económicos y políticos: el contencioso territorial relativo a las ciudades de Ceuta y Melilla, la cuestión del Sáhara Occidental la cual no llega a tener solución debido a las disputas entre Marruecos y el Frente Polisario, los conflictos periódicos en torno al tema de la pesca y la competencia de ciertos productos hortofructícolas son controversias todavía irresueltas.

De más reciente origen son los problemas relativos al tráfico de droga hacia el sur de España desde la región marroquí del Rif y el fuerte flujo de emigrantes ilegales hacia España a traves del estrecho de Gibraltar. De hecho España, reconociendo la existencia de fuertes interdependencias en los intereses compartidos con Marruecos (desde el crecimiento económico hasta la estabilidad en el área del Mediterráneo), ha empezado a prestar una atención particular a este país desde la década de los años 80 .

El resultado ha sido una política exterior española dirigida a reactivar la colaboración en el Mediterráneo, sea en el contexto multilateral, sea en el de las relaciones bilaterales con Marruecos. Con estos propósitos, los primeros encuentros diplomáticos entre España y Marruecos tuvieron lugar en 1767, año de la firma del primer Tratado de Paz y Comercio entre los dos. Un Tratado definido como canónico, con el cual los monarcas Carlos III y Mohamed Ben-Abdala lograron un compromiso de paz estable, basado sobre reglas a respetar en el intercambio comercial entre los puertos españoles y marroquíes.

Desde principios de los años 80 el repertorio de tratados, convenios y acuerdos entre España y Marruecos empezó a ampliarse. Antes de esta fecha es de destacar el «Convenio en materia de cooperación científica y técnica» (BOE de 1 diciembre 1979), firmado el 8 de noviembre de 1979, que entró en vigor en enero de 1981. Se trata de un compromiso entre las partes para favorecer y facilitar la realización de programas de cooperación científica y técnica a través del intercambio de know-how. Todo ello en el marco del desarrollo económico y social de España y Marruecos instrumentalizado a través de la formación e investigación. Además, el convenio propone algunas medidas a desarrollar como becas, intercambio de documentación y de información técnico-científica, así como, utilización en común de instalaciones científicas y técnicas.

$\mathrm{El}$ «Convenio sobre la Cooperacion cultural» (BOE de 10 octubre 1985), firmado el 14 de octubre de 1980, entró en vigor en septiembre de 1985, señala el inicio de una nueva era, en la cual se advierte la voluntad de España y Marruecos de incrementar la comprensión entre sus pueblos. Con la finalidad de promover el conocimiento de su bagaje cultural y patrimonial, el convenio establece una serie de opciones como: 1) la cooperación entre las instituciones culturales respectivamente reconocidas; 2) la publicación conjunta de obras literarias que avalan las civilizaciones de estos pueblos; 3) la difusión de la historia de los dos países a través de la inserción de ésta en sus programas oficiales; 4) cooperación e investigación científica a través del intercambio de profesores; 5) formación de los cuadros marroquíes a través de períodos de prácticas en empresas o instituciones de enseñanza españolas.

$\mathrm{El}$ «Convenio sobre cooperación técnica y asistencia mutua en materia de Protección Civil» (BOE de 22 de febrero 1993) es el primer documento suscrito por los dos países después de la adhesión de España a la Comunidad Europea en enero de 1986. Un momento particular que evoca la voluntad de la clase política dirigente de contribuir a la prosperidad y estabilidad de los estados en el área del Mediterráneo. Este convenio, firmado en Rabat el 21 de enero de 1987 y entrado en vigor en 1992, se tradujo en un acuerdo entre España y Marruecos para promover acciones conjuntas y coordinadas en el marco de programas y 
proyectos de cooperación técnica en materia de Protección Civil. De nuevo emerge la intención de favorecer una cooperación a través de intercambio de información, encuentros, envío de técnicos para la prestación de servicios de consulta. La peculiaridad de este convenio deriva del artículo 2 del mismo donde las dos partes se comprometen a prestarse ayuda civil en caso de emergencia o catástrofe. En otras palabras, esta colaboración es entendida como un socorro logístico recíproco a efectuar reduciendo al mínimo las formalidades de paso de frontera y concediendo permisos para operar en las zonas afectadas.

Sin embargo, el período más significativo en las relaciones políticas hispano-marroquíes tiene su inicio en 1991. Un año intenso marcado por dos momentos importantes: en primer lugar, a partir del 15 de mayo de 1991 España impone la obligación de visados a los ciudadanos del Magreb; en segundo lugar, desde el 10 de junio del mismo año los inmigrantes clandestinos e ilegales pueden contar con un segundo proceso de regularización.

En este contexto, el «Tratado de amistad, buena vecindad y cooperación entre el Reino de España y el Reino de Marruecos» (BOE de 26 de febrero 1993), hecho en Rabat el 4 de julio de 1991 y entrado en vigor en enero de 1993, sintetiza toda la filosofía de nueva inspiración del enlace hispano-marroquí. La primera parte describe el escenario en el que han tenido lugar las relaciones entre ambos estados, en particular los motivos que les han impulsado. En la segunda parte, dispone los principios generales en los que tienen que basarse las nuevas relaciones en el futuro: 1, respeto a la legalidad internacional; 2, igualdad soberana; 3 , no intervención en los asuntos internos; 4, abstención de recurrir a la amenaza o al uso de la fuerza; 5 , arreglo pacífico de controversias; 6 , cooperación para el desarrollo; 7, respeto a los derechos humanos y a las libertades fundamentales de las personas; 8, diálogo y comprensión entre culturas y civilizaciones. Finalmente, la tercera parte está compuesta por dos capítulos, uno sobre las relaciones políticas bilaterales y otro sobre las relaciones de cooperación en materias económica-financiera, defensa, cultura, aspectos jurídicos consulares y desarrollo.

Respecto a la entrada ilegal, a la residencia y al tránsito de extranjeros sobre los territorios de España y Marruecos son de destacar dos acuerdos: "Acuerdo relativo a la circulación de personas, el tránsito y la readmisión de extranjeros entrados ilegalmente» (BOE de 25 de abril 1992), firmado el 13 de febrero de 1992 y que entró provisionalmente en vigor en la misma fecha y el «Acuerdo en materia de permisos de residencia y trabajo» (BOE de 28 de mayo 1996), firmado en Rabat el 6 de febrero de 1996 y que entró en vigor provisionalmente en la misma fecha. El primero fue redactado para satisfacer el deseo conjunto de coordinar las políticas destinadas a detener el flujo migratorio clandestino entre España y Marruecos. Así pues, en el primer capítulo el convenio individualiza la posibilidad de readmitir a los ciudadanos provenientes de terceros países entrados ilegalmente en uno de éstos países. Readmisión que debe ser efectuada cuando las autoridades de la frontera del estado de origen del ilegal, la requieren formalmente. Los artículos 2 y 3 del acuerdo detallan los supuestos y formas de readmisión, subrayando la importancia del nexo entre el origen del ilegal y el estado que solicita su readmisión. En cambio, en el segundo capítulo, las partes contratantes admiten la posibilidad de entrada y tránsito para la expulsión de nacionales de países terceros, cuando la continuación del viaje y su admisión en el Estado de destino estén plenamente aseguradas. El segundo acuerdo, de febrero 1996, establece que los ciudadanos de España y Marruecos, en base al principio de reciprocidad, tienen acceso a los permisos de residencia con 1 año de duración con posibilidad de una primera renovación de 2 años y una segunda renovación de tres años. Además, los nacionales de ambos países, con una residencia continuada de 6 años, tienen derecho a un permiso de residencia permanente.

Finalmente, el más reciente es el «Convenio de extradición entre el Reino de España y 
el Reino de Marruecos» (BOE de 25 de junio 1997), firmado en Madrid el 30 de mayo de 1997 y que entró en vigor provisionalmente a partir de la misma fecha. En éste las partes contratantes se comprometen a otorgar la extradición de las personas procesadas o condenadas en el territorio de uno de los Estados. El convenio fija los hechos que dan lugar a la extradición, los motivos por los cuales se puede denegar obligatoriamente y facultativamente la misma y el procedimiento a seguir.

Por lo que atañe a las relaciones económicas hispano-marroquíes, la principal característica de la cooperación financiera entre los dos países son los fondos que España ha puesto a disposición de Marruecos, primero con el acuerdo de 1988 y más recientemente con el acuerdo de 1996. El «Acuerdo de cooperación económica y financiera» de 1988 recogía el compromiso español de conceder a Marruecos créditos por valor de 125.000 millones de pesetas por un período de 5 años, y a destinar a: 1. la adquisición de bienes y servicios españoles; 2 . la realización de proyectos comunes en materia de equipamiento de infraestructuras, transportes y sistemas de telecomunicaciones; 3 . la mejora de la productividad de determinados sectores económicos claves de Marruecos.

Análogamente, con el «Acuerdo de cooperación económica y financiera» de 1996 España pone a disposición de Marruecos efectivos financieros por un valor de 150.000 millones de pesetas con los mismos objetivos que en el acuerdo anterior y hasta el año 2001. Se preveen formas de financiación estructuradas en el siguiente modo: a) 60.000 millones de pesetas de crédito del Fondo de Ayuda al Desarrollo (FAD); b) 90.000 millones de pesetas de crédito para la exportación en las condiciones de consenso de la OCDE.

En general hasta hoy, los créditos totales españoles en favor de Marruecos (créditos comerciales más préstamos en divisas) han tenido un tránsito fluctuante. España, después de haber duplicado la concesión de créditos de 1991 a 1992 y haber concedido en 1993 un crédito total de 2.239 millones de dirham, en 1995 ha reducido el volumen de financiación a 221,7 millones de dirham.

En el contexto multilateral de las relaciones exteriores de la U.E., España ha insistido sobre la profundización de medidas en favor del Mediterráneo, jugando la carta del equilibrio geográfico y estratégico. En este contexto, a pesar de ser este foro el más significativo, su acción multilateral no se ha reducido sólo a su labor en el seno de la Unión Europea.

Además, España ha formado parte del Grupo de diálogo 5+5 que ha englobado en los últimos años a cinco países de cada una de las orillas del Mediterráneo (España, Francia, Italia, Portugal y Malta por un lado, y Argelia, Libia, Marruecos, Mauritania y Túnez por el otro), como instrumento de aproximación regional en el Mediterráneo Occidental.

En particular, España ha contribuido al diseño de la nueva Política Mediterránea, participando activamente en la celebración de la Conferencia de Barcelona en noviembre de 1995, cuyas resoluciones constituyen, hoy en día, el punto de partida de una nueva etapa en las relaciones con los Terceros Países del Mediterráneo. En la Declaración final de dicha Conferencia, los participantes se mostraban convencidos de la necesidad de instaurar una Asociación Euro-mediterránea, superando las insuficiencias de los esquemas anteriores. Para ello, actualmente todos las acciones de los países ribereños del Mediterráneo tienen como fin una asociación global, articulada en torno a tres aspectos claves: a) la colaboración política y de seguridad, b) la colaboración económica y financiera, c) la colaboración social y cultural. Por lo que se refiere al segundo frente, la Conferencia se fijó, como objetivo a largo plazo, la creación progresiva de un «Área de libre comercio» hasta el año 2010, a llevarse a cabo a través de la adopción de unos nuevos Acuerdos de Asociación Euro-mediterránea entre la UE y los diferentes PTM.

Con respecto a Marruecos, el 1 enero de 1997 entró en vigor el nuevo acuerdo entre 
este país y la Unión Europea, cuyo objetivo fundamental es la instalación del libre comercio entre los dos interesados, mediante la reciprocidad de concesiones comerciales referentes a los productos manufacturados. En otras palabras, Marruecos se comprometería a suprimir progresivamente, de 1997 a 2009, todos los derechos e impuestos de efecto equivalente, para la totalidad de los productos industriales procedentes de la UE. Por lo tanto, el carácter bilateral en las concesiones comerciales es una importante novedad introducida en el nuevo acuerdo, a lo que hay que unir una cooperación financiera creciente. Otra innovación de esta nueva política es que los países mediterráneos no comunitarios pueden disponer de un plan financiero de mayor envergadura que asciende a 4.685 millones de ECU para el periodo 1995-1999.

En el marco del Programa MEDA (que individualiza la línea presupuestaria única para obtener fondos comunitarios), Marruecos se beneficiará de una cobertura financiara de 450 millones de ECU (alrededor de 600 millones de dólares) para el 1996-98.

En conclusión, es el momento de la apertura de la economía marroquí, la cual implicará un esfuerzo por parte del gobierno de Marruecos para que se corrigan, sobre todo, los desequilibrios macroeconómicos. Sin embargo, esta apertura está inscrita tanto en el Acuerdo de Asociación Marruecos-UE como en los Acuerdos bilaterales España-Marruecos, hecho que es inevitable para el desarrollo de un Mediterráneo de seguridad y paz.

\subsection{Los proyectos de Andalucía en favor de los marroquíes}

La experiencia de cooperación entre Andalucía y Marruecos ha tenido su origen en los años recientes, aunque han existido tradicionales enlaces ribereños entre sus poblaciones. El motivo de este retraso se debe a dos factores. En primer lugar, Andalucía tradicionalmente ha sido sólo una zona de paso para el tránsito de los inmigrantes marroquíes interesados en realidad en alcanzar los países más desarrollados de Europa y las regiones más ricas de España; en segundo lugar, esta comunidad autónoma ha utilizado durante muchos años los acuerdos entre el Gobierno Central español y Marruecos, porque éstos le permitían gestionar la presencia marroquí en su área, sin tener que recurrir a intervenciones directas con el país vecino.

Así pues, sólo a partir de la segunda mitad de los años 90, tras el proceso de regularización de los extranjeros y con la presencia de un fuerte número de marroquíes en los campos andaluces, la Junta de Andalucía ha empezado a presentarse como interlocutor directo con Marruecos.

En este contexto se encuadran las principales iniciativas entre estas Administraciones, y que son: 1) la Declaración de Intenciones para la cooperación entre la Administración de la Junta de Andalucía y el Reino de Marruecos, firmada el 11 de noviembre de 1996; 2) el Convenio Marco de colaboración suscrito entre la Junta de Andalucía y la Agencia Española de Cooperación Internacional del Ministerio de Asuntos Exteriores, de 27 de octubre 1997; 3) el reciente Memorándum de entendimiento entre la Agencia para la Promoción y el Desarrollo Económico y Social de las Prefecturas y Provincias del Norte del Reino del Marruecos y la Administración de la Junta de Andalucía, firmada el 5 de febrero de 1998. Por lo que atañe a este último acuerdo, su objetivo es el de fomentar iniciativas empresariales conjuntas y de cooperación entre los agentes de desarrollo económico, a fin de contribuir al progreso de las regiones del norte de África. De hecho, el convenio pretende sostener una colaboración para que en el país magrebí se pongan en práctica experiencias ya existentes en Andalucía.

En el marco de cooperación entre la Agencia para la Promoción y el Desarrollo Económico y Social de las Prefecturas y Provincias del Norte del Reino de Marruecos y la 
Consejería de Trabajo e Industria de la Junta de Andalucía a través de la IFA (Instituto de Fomento de Andalucía), el Memorándum individualiza los programas de trabajo y las áreas de actuación en las que se debería desarrollar esta colaboración. Con este propósito, la asistencia a empresas del Norte de Marruecos, la formación del personal de estas empresas, junto al intercambio de información sobre iniciativas de empresas marroquíes o andaluzas son algunos de las áreas prioritarias para dicha cooperación.

Por otra parte, de los proyectos financiados por la Junta de Andalucía en el año 1997, cuatro de ellos ya estaban en curso de realización, a los que se ha destinado un apoyo financiero de 50 millones de pesetas (Programa MEDELCO, Proyecto de cooperación en el ámbito energético y de la industria, Proyecto de rehabilitación de la Medina de Tetuán y Proyecto de rehabilitación de la Medina de Chefchauén).

Finalmente, no se puede olvidar la obra de cooperación a nivel social, realizada por las asociaciones de acogida y asistencia que atienden a los inmigrantes en Andalucía. Estas tienen un origen reciente, al constituirse la mayoría en la década de los noventa, con la intención de ayudar a los inmigrantes no regularizados en el año 1991. Desde entonces, estas organizaciones han experimentado un crecimiento rápido y un desarrollo constante. Además se deben tener en cuenta otras asociaciones como la ONG Andalucía Acoge que fue pionera en asistir a los inmigrantes, existiendo ya desde mediados de los años ochenta. En particular, Andalucía Acoge se presenta hoy como una federación compuesta por nueve organizaciones no gubernativas, distribuidas sobre todo el territorio andaluz, que se preocupan no sólo del servicio de asistencia y de distribución de vivienda, sino también de actividades formativas, de asistencia médica y de educación familiar.

\section{Conclusiones}

España, en virtud de su posición geográfica, desde siempre es un punto de paso para pueblos que han descubierto en la movilidad una forma de vida, enfatizando últimamente el aporte económico. Este país ha experimentado durante muchos años migraciones de entrada y salida, hasta transformarse a partir de la segunda década de los años 80 en país de inmigración. En particular, la historia reciente migratoria de España ha estado marcada por la llegada de los inmigrantes africanos: entre estos, después de la regularización de 1991, el contingente que ha crecido más ha sido el marroquí, actualmente en la primera posición del ranking de los residentes y trabajadores extranjeros. Se trata de un colectivo que se dirige hacia el sur de España, en concreto hacia Andalucía, esencialmente por la proximidad de su litoral a las costas de las regiones septentrionales de Marruecos. De hecho, a través de esta puerta los marroquíes pueden acceder a otras comunidades autónomas españolas, aunque a partir de los años 90 Andalucía está viviendo el fenómeno de la permanencia definitiva de los inmigrantes africanos.

En cuanto al perfil demográfico de los marroquíes que viven en Andalucía, se ha observado a través de investigaciones sobre el terreno que actualmente el contingente de estos inmigrados se caracteriza por la presencia conjunta de hombres y mujeres, mayoritariamente no casados y sobre todo interesados en enviar a su patria sus salarios o bienes de consumo. A estos se deben adjuntar los núcleos familiares que residen principalmente en las ciudades donde pueden integrarse más fácilmente y participar en actividades formativoculturales. Finalmente, no se puede olvidar a los marroquíes clandestinos o en condición irregular, todavía preocupante realidad para las autoridades andaluzas. Con respecto a los clandestinos, continúan afrontando viajes precarios, privándose de todos sus bienes y enriqueciendo a los llamados «passeurs»; en cambio, los irregulares viven de trabajos estacionales en los invernaderos, favoreciendo el «mercado de trabajo negro». 
Con tal propósito, en el plano legislativo y operativo, el Gobierno Español ha intentado responder a la «emergencia-irregulares», estableciendo controles más severos en las fronteras marítimas e interviniendo con regularizaciones o política de ubicación de extranjeros en el mercado de trabajo (como la política de contingentes). Análogamente, del estudio de los textos jurídicos y de los documentos de compromiso entre España y Marruecos, se observa que entre los dos países existe una relación histórica, la cual persevera y se intensifica con el fin de solucionar el problema del movimiento masivo de los marroquíes hacia España. Al contrario, en el contexto más específico de la colaboración entre Andalucía y Marruecos, se nota un retraso por parte del gobierno andaluz en la adopción de medidas a favor de la comunidad marroquí. Los primeros acuerdos entre los dos países surgen sólo en los años 1996 y 1997, aunque se debe tener en cuenta el papel desempeñado por las ONG.

En general, en lo referente a la política de cooperación, el principio fundamental más asentado es el de «un equilibrado y solidario reparto de los deberes entre los países miembros de la UE», con el fin de alcanzar una efectiva «comunitarización» de la política de migraciones. Sin embargo, si la política internacional centralista y unidireccional se podía considerar un importante instrumento de contención de las migraciones en el pasado, es opinión común que hoy en día hace falta integrarla con una nueva modalidad de cooperación, o sea la descentralizada. En otras palabras, se trata de implicar a los sujetos institucionales y económicos de los diversos países destinatarios de ayudas, negociando con ellos a través de un «partenariado» activo.

En conclusión, si las restricciones a la inmigración llevadas a cabo por algunos países de la UE no fueran acompañadas de adecuadas políticas de apoyo a la economía de los países de emigración, jel final de este milenio estará marcado por un número siempre creciente de movimientos humanos procedentes de la ribera sur del Mediterráneo! ¡En este escenario España es punto de mira! En el momento en que Marruecos se quede en «el punto ciego de nuestras conciencias», España no podrá eludir a la gente de las pateras, errante en el mundo en busca sólo de dignidad.

\section{Bibliografía}

AA. VV., (1994): Annuaire de l'emigration, Fondation Hassan II, Rabat, Marruecos.

CHECA, F. (Edit.) (1998): Africanos en la otra orilla, Icaria Editorial, Barcelona.

COHEN, A. (1995): «Algunas reflexiones a propósito de la inmigración magrebí en España», Ería, $\mathrm{n}^{\circ} 38$, Universidad de Oviedo.

CORDERO DEL CASTILLO, P. (1993): «Una síntesis y explicación de la inmigración en España», Polígonos, $\mathrm{n}^{\circ} 3$, Universidad de León.

GARCÍA MARTÍNEZ, C. (1997): «España, país de inmigración», Colección Estudios, nº 40, Universidad de Castilla la Mancha.

GÓMEZ LÓPEZ, J.D.; SEGRELLES SERRANO, J.A. (1993): «La situación de la mano de obra marroquí en los invernaderos del Campo de Dalías (Almería)», Immigración extranjera y planificación demográfica en España, Departamento de Geografía de la Universidad de La Laguna y Grupo de Población de la AGE.

GOZÁLVEZ PÉREZ, V. (1993): «La inmigración magrebí en Europa. El caso de España» Polígonos, Revista de Geografía, no 3, Universidad de León.

GOZÁLVEZ PÉREZ, V. (Dir.) (1995): Inmigrantes marroquíes y senegaleses en la España mediterránea, Generalitat Valenciana, Valencia.

GOZÁLVEZ PÉREZ, V. (1995): «L'immigration maghrébine en Espagne», a cura di L. Di Comite, Quaderno 9, Dipartimento per lo Studio delle Societá mediterranee, Universitá di Bari.

GOZÁLVEZ PÉREZ, V. (1996): «L'immigration africaine en Espagne: l'entrée par la frontière meridionale», Quaderno 11, Dipartimento per lo Studio delle Societá mediterranee, Universitá di Bari. 
GOZÁLVEZ PÉREZ, V. (1996): «L’inmigration etrangère en Espagne (1985-1995)», Revue Europeéenne des Migrations Internationales, vol. 12, $\mathrm{n}^{\circ}$ 1, Université de Poitiers.

GOZÁLVEZ PÉREZ, V., DOMINGO PÉREZ, C. (1996): «La inmigración magrebí en España: actualidad y futuro», Boletín de la Asociación de Geógrafos Españoles, no 23.

GOZÁLVEZ PÉREZ, V., LÓPEZ TRIGAL, L. (1998): «Jornaleros extranjeros en el campo español», Ería (en prensa).

IZQUIERDO ESCRIBANO, A. (1994): Causas y consecuencias de los movimientos migratorios en «La intervención con inmigrantes desde los servicios sociales comunitarios», Junta de Andalucía, Sevilla.

IZQUIERDO ESCRIBANO, A. (1996): La inmigración inesperada: la población extranjera en España 1991-1995, Editorial Trotta, Madrid.

LÓPEZ GARCÍA, B. (1996): Atlas de la inmigración magrebí en España, Universidad Autónoma de Madrid, Ministerio de Asuntos Sociales, Madrid.

MARTÍNEZ, M.F.; GARCÍA, M.; MAYA, I.; RODRÍGUEZ, S.; CHECA, F. (1996): La integración social de los inmigrantes africanos en Andalucía, Universidad de Sevilla, Junta de Andalucía.

Ministère des Affaires Etrangers (1998): Les relations economiques et financières Maroc-Espagnoles, Direction des Affaires Européennes, Rabat, Marruecos.

Ministerio de Trabajo y Asuntos Sociales, Anuario des migraciones, (varios años), Dirección General de Migraciones, Madrid.

Ministerio del Interior, Anuario Estadístico de Extranjería 1996, Comisión Interministerial de Extranjería, Madrid.

Ministerio del Interior, Estadística de Extranjería 1996, Dirección General de la Policía, Madrid.

MORALES LEZCANO, V. (1993): España y el mundo árabe: imágenes cruzadas, Agencia Española de Cooperación Internacional, Madrid.

RAMÍREZ, E. (1996): Inmigrantes en España: vidas y experiencia, CIS, Madrid.

PONCE HERRERO, G.; VALERO ESCANDELL, J.R.; PALAZÓN FERRANDO, S. (1996): «Marroquíes en Cataluña. Estrategias selectivas de integración: la gran ciudad, los núcleos industriales y los municipios menores», Boletín de la Asociación de Geógrafos Españoles, n 23, Madrid.

PUMARES FERNÁNDEZ, P. (1996): «Repercusiones del uso del espacio en las relaciones entre españoles e inmigrantes extranjeros», Boletín de la Asociación de Geógrafos Españoles, n 23, Madrid.

PUMARES FERNÁNDEZ, P. (1998): «QQué es la integración? Reflexiones sobre el concepto de integración de los emigrantes» en CHECA, F. (Edit.): Africanos en la otra orilla, Icaria, Barcelona. 